\title{
(2) OPEN ACCESS \\ Economic, clinical and social impact of simple limbal epithelial transplantation for limbal stem cell deficiency
}

\author{
Praveen Thokala, ${ }^{1}$ Aastha Singh, ${ }^{2}$ Vijay Kumar Singh, ${ }^{3,4}$ Varsha M Rathi $(0)$, \\ Sayan Basu (1) , ${ }^{3,6}$ Vivek Singh 다, ${ }^{3,4}$ Sheila MacNeil, ${ }^{7}$ Virender Singh Sangwan ${ }^{8}$
}

\begin{abstract}
- Additional material is published online only. To view please visit the journal online (http://dx.doi.org/10.1136/ bjophthalmol-2020-318642).
\end{abstract}

For numbered affiliations see end of article.

Correspondence to Dr Sheila MacNeil, Department of Materials Science \& Engineering, The University of Sheffield Kroto Research Institute, Sheffield, UK: s.macneil@sheffield.ac.uk, Dr Vivek Singh, Center for Ocular Regeneration, Prof. Brien Holden Eye Research Center, LV Prasad Eye Institute, Hyderabad, Telangana, India; viveksingh@lvpei.org and Dr Virender Singh Sangwan, Dr Shroff's Charity Eye Hospital Delhi, New Delhi, India; virender.sangwan@sceh.net

Received 15 December 2020 Revised 21 January 2021 Accepted 5 February 2021
D) Check for updates

(C) Author(s) (or their employer(s)) 2021. Re-use permitted under CC BY-NC. No commercial re-use. See rights and permissions. Published by BMJ.

To cite: Thokala P, Singh A, Singh VK, et al.

Br J Ophthalmol Epub ahead of print: [please include Day Month Year]. doi:10.1136/ bjophthalmol-2020-318642

\begin{abstract}
Aims To report the global uptake of simple limbal epithelial transplantation (SLET) and compare the economic, clinical and social outcomes of SLET with those of cultured limbal epithelial transplantation (CLET). Methods A comprehensive literature review and an online survey of eye surgeons were conducted to understand the efficacy and current uptake of SLET surgery. A de novo economic model was developed to estimate the cost savings with SLET compared with CLET. Our economic analysis is conducted from an Indian perspective, as this is where the technique originated. A scenario analysis using the UK cost data and a userfriendly Excel model is included to allow users to input the costs from their setting to estimate the cost savings with using SLET compared with using CLET
\end{abstract}

Results The anatomical success with SLET in adults (72.6\% (range 62\%-80\%)) was the same as CLET $(70.4 \%$ (range $68 \%-80.9 \%))$. For children, the outcome for SLET $(77.8 \%$ (range $73 \%-83 \%)$ ) was better than with CLET $(44.5 \%$ (range $43 \%-45 \%)$ ). In response to our informal questionnaire, 99 surgeons reported to have performed SLET on 1174 patients in total. They appreciated that SLET negates the requirement for costly tissue engineering facilities. Results of economic analysis suggested that SLET provided an estimated cost-savings of US $\$ 6470.88$ for adults and US\$6673.10 for children. In broad terms, the cost of SLET is approximately $10 \%$ of the cost of CLET for adults and 8\% for children.

Conclusion SLET offers a more accessible and financially attractive alternative to CLET to treat limbal stem cell deficiency.

\section{INTRODUCTION}

Limbal epithelial stem cells play a critical role in preserving the health of the corneal epithelium. In addition to refreshing the cells, they act as a barrier to prevent conjunctivalisation and vascularisation of the cornea that may result in loss of clarity. Damage or loss of these epithelial cells can thus lead to potentially severe visual impairment due to a condition termed limbal stem cell deficiency (LSCD). ${ }^{12}$

Cultivated limbal epithelial transplantation (CLET) is a procedure of transplanting autologous laboratory-expanded limbal epithelial stem cells to replace conjuctivalised cornea with cultured epithelial cells. After 2-3 weeks of cell expansion, the cultured cells are transplanted onto the patient's affected eye, most commonly using human donor amniotic membrane which often integrates into the corneal stroma without completely disappearing leaving the cultured cells attached to the underlying corneal stroma. Recently, a fibrin scaffold has been used for the delivery of cultured cells. ${ }^{3}$

CLET has an impressive success rate, however, it requires highly specialised tissue culture expertise and Good Manufacturing Practice facilities for the ex vivo expansion of the cells incurring significant costs for establishing specialist facilities/equipment, consumables and highly skilled labour. These facilities used for ex vivo expansion of cells must also operate under a strict set of regulations that require considerable ongoing investment. It is also a twostage procedure, wherein after retrieving the donor cells from the patient, cells are expanded over 2-3 weeks in the laboratory after which they are transplanted to the affected eye.

In 2012, a novel procedure termed simple limbal epithelial transplantation (SLET) was proposed for patients with LSCD, where small pieces of tissue from the limbus of the healthy eye of the patient are directly transplanted into the affected eye, after surgically removing abnormal tissue, in a single surgery. ${ }^{4}$ SLET still needs the use of amniotic membrane to support the cell outgrowth from the pieces of limbal tissue but does not require any ex vivo tissue expansion nor a second surgery. Several SLET training workshops have now been conducted both in India and internationally, and as a result, SLET is now beginning to be used around the world.

It is suggested that SLET can overcome the challenges of establishing CLET and reach more patients as it does not require regulatory approval related to ex vivo expansion of cells and only requires a single surgery (compared with two surgeries in CLET) alleviating demands on the healthcare system and the patient. However, to our knowledge, no study has comprehensively estimated the clinical, economic and social impact of using SLET versus CLET for patients with LSCD.

The aim of this study is to estimate and report the economic, clinical and social impact of SLET in comparison with CLET.

\section{MATERIALS AND METHODS}

A multidisciplinary approach using mixed methods was used to estimate the clinical, economic and social impact of using SLET versus CLET for patients with LSCD. The clinical impact relates 
Table 1 Clinical outcomes of cultured limbal epithelial transplantation and simple limbal epithelial transplantation

\begin{tabular}{|c|c|c|c|c|c|c|}
\hline Author & Year & Country & $\mathrm{N}$ & Anatomic success (\%) & Functional success $(\%)$ & Mean follow-up in years (range) \\
\hline \multicolumn{7}{|c|}{ Cultured limbal epithelial transplantation outcomes } \\
\hline Rama et $a^{40}$ & 2010 & Italy & 107 & 68 & 54 & $2.9(1-9.4)$ \\
\hline Paulkin et $a l^{41}$ & 2010 & Italy & 30 & 77 & 73 & $2.4(0.8-6)$ \\
\hline Sangwan et $a l^{4}$ & 2011 & India & 200 & 71.4 & 60.3 & $3(1-7.6)$ \\
\hline Sejpal et $\left.a\right|^{35}$ & 2012 & India & 107 & 37 & NA & $3.4(1-9.8)$ \\
\hline Ganger et $\left.a\right|^{36}$ & 2015 & India & 54 & 72 & 23 & $1.8(0.3-3.3)$ \\
\hline Fasolo et $a^{42}$ & 2017 & Italy & 59 & 42 & NA & $6(1-13)$ \\
\hline \multicolumn{7}{|c|}{ Simple limbal epithelial transplantation outcomes } \\
\hline Basu et al ${ }^{13}$ & 2016 & India & 125 & 76 & 75 & $1.5(1-4)$ \\
\hline Vazirani et al ${ }^{17}$ & 2016 & Multicentre & 68 & 84 & 65 & $1(0.5-4.9)$ \\
\hline Gupta et $a l^{23}$ & 2018 & India & 30 & 70 & 50 & $1.1(0.5-3.4)$ \\
\hline Basu et $a l^{22}$ & 2018 & India & 30 & 80 & NA & $2.3(0.8-3.8)$ \\
\hline
\end{tabular}

to the efficacy and current uptake of SLET surgery around the world; the economic impact relates to the costs associated with both procedures, and the social impact relates to the benefits to the patients and the healthcare system.

\section{Methods for the estimation of clinical impact Literature review}

A literature review using search terms related to SLET in PubMed and Cochrane Library was conducted in May 2020 by two researchers (AS and VijayS) working independently to minimise the possibility of relevant studies being missed. From the studies identified in the review, data on the clinical effectiveness of SLET, the country/setting and the number of patients treated with SLET were extracted. To compare the clinical outcomes, we purposefully selected clinical studies with at least 30 patients and at least 1 or more years follow-up (table 1 ).

\section{Questionnaire-based survey}

In addition to surveying the published peer-reviewed literature, we obtained institutional permission to survey surgeons concerning their use of SLET (Ethics ref no LEC BHR-P-0420-414). An iterative process was used in developing the set of questions regarding the surgeons' country/setting, the number of years of experience of conducting eye surgery, experience with SLET and CLET, availability of cell culture facilities and their opinions on SLET. The questionnaire was converted into an online survey specifically to target surgeons who attended a SLET workshop in recent years. The data gathered from the survey were collated and analysed to understand the uptake of SLET.

\section{Estimation of the economic impact}

Pathways of both surgeries were developed, and bottom-up costing was used to populate a de novo economic model to estimate the total costs of each procedure from a healthcare system perspective.

An iterative approach using process mapping techniques was used to understand the pathways involved in SLET and CLET. First, draft pathways were specified, based on the findings of the literature review, by researchers with knowledge of SLET and CLET. These were presented to clinical experts for feedback, and a final list of steps associated with SLET and CLET was put together (figure 3). A brief description of each of the steps was also presented to the clinicians to ensure the validity of resource use and costs associated with each step.
The total costs for SLET and CLET were estimated using bottom-up costing that is, by capturing and aggregating the costs associated with each of the steps. The costs were estimated from an Indian perspective, using the costs from the LV Prasad Eye Institute (LVPEI), Hyderabad, India for the base case analyses. A de novo economic model was developed in Microsoft Excel to estimate the total costs associated with SLET and CLET. Uncertainty in the costs was captured using parametric distributions and probabilistic sensitivity analyses were performed to estimate the robustness of the total cost estimates. Scenario analyses were also performed using costs from India and UK.

\section{Estimation of the social impact}

To understand the health system impact of SLET surgery compared with CLET, the lead clinicians involved in this study were interviewed and we also solicited comments, both good and bad, from surgeons who responded to our questionnaire.

\section{RESULTS}

\section{Clinical impact of LSCD}

Literature review

The literature searches identified 83 studies in which SLET outcomes were measured. After screening at the title and abstract level, 79 articles remained and of these 30 articles remained after a full-text examination. The Preferred Reporting Items for Systematic Reviews and Meta-Analyses diagram is presented in figure 1. An overview of the included studies and the data extracted is presented in online supplemental appendix 1 .

The review identified 30 studies, ${ }^{4-33}$ covering 8 countries and a total of 432 patients reported as receiving SLET. The median follow-up in the largest case series (125 cases, Basu et al) was 1.5 years (range $1-4$ years) ${ }^{13}$ and the longest reported follow-up period was 4.9 years. ${ }^{17}$ The number of patients who received SLET surgery estimated from the questionnaire is 1315 which is much higher than those reported in the peer-reviewed literature as expected. The cumulative number of published studies and patients treated with SLET are shown in figure 2A,B, respectively.

The clinical outcome of SLET/CLET is reported as anatomical success which refers to re-establishment of a completely epithelised, stable and avascular corneal surface and functional success which refers to improvement in best-corrected visual acuity of two-lines or greater. ${ }^{34}$ Anatomical and functional success in six studies of CLET and four studies of SLET, which involved at least 30 patients with a clinical follow-up of at least 1 year, is summarised in table 1 . The mean anatomic success of cases 


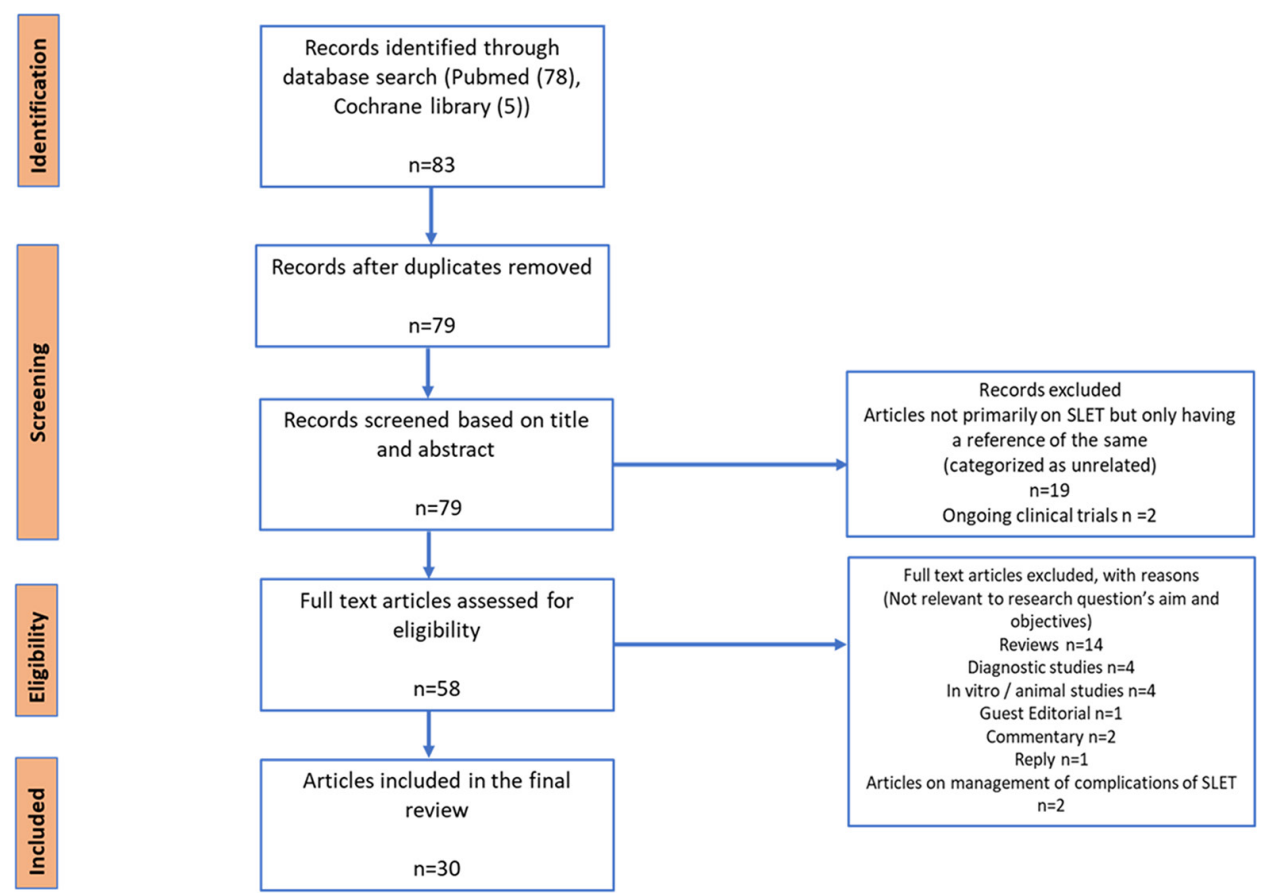

Figure 1 Preferred Reporting Items for Systematic Reviews and Meta-Analyses diagram for the simple limbal epithelial transplantation literature review.

was $78 \%$ (range $76 \%-84 \%$ ) and the mean functional success of cases was $68.6 \%$ (range 50\%-75\%) which demonstrated clinical equivalence to CLET which has been reported to have anatomic success in $61.4 \%$ cases (range $37 \%-77 \%$ ) and functional success in $51.5 \%$ cases (range $17 \%-70 \%$ ). ${ }^{34}$ Four studies reported a greater clinical benefit of using SLET instead of CLET when assessing outcomes for paediatric patients. ${ }^{5} 131424$

\section{Questionnaire survey}

Out of the 294 members of the Ocular Surface group of ophthalmologists (http://www.corneasociety.org), 99 belonging to different institutes, hospitals and individual clinics responded to this questionnaire. As SLET was discovered in India and most of the SLET workshops/Wet-labs/ Training Courses were conducted in India, the majority of the surgeons were from India (91) but we also had the participation of surgeons from the USA (1), Mexico (3), Oman (1), Austria (1), Colombia (1), and Greece (1).

Of these $87 \%$ of surgeons had undertaken SLET surgery for the treatment of 1174 patients with LSCD, with 29\% of surgeons undertaking the surgery in less than 5 patients, $35 \%$ in
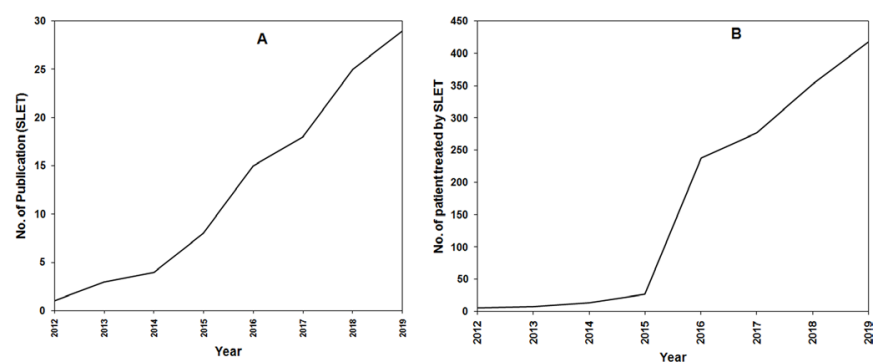

Figure 2 Publication pattern of SLET studies over the years 2012-2019. (A) Number of published papers over years. (B) Number of patients treated with SLET estimated from published studies. SLET, simple limbal epithelial transplantation.
5-10 patients, 32\% in 11-50 patients and 2\% with experience of SLET in more than 50 patients.

In response to the clinical experience of SLET, 1\% surgeons were unhappy, $56 \%$ reasonably happy and $43 \%$ were very happy with the SLET procedure. Surgeon's comments regarding their experience with SLET were that the procedure is convenient, easy, cost-effective, scientific, efficient, reliable and reproducible. A few surgeons stated that there is a learning curve for SLET and there are issues of acceptance, vascularisation from the edges and unusual responses in paediatric cases. The detailed analysis of the results from the questionnaire-based survey is shown in online supplemental appendix 2 .

\section{Economic analysis}

A brief description of the steps involved in SLET and CLET is presented in figure 3 , and a summary of the costs is presented in table 2 , and these are described in more detail in online supplemental appendix 3 .

\section{Cost data}

The costs in Indian rupee (INR) associated with each of the steps involved in SLET and CLET established in the running of one large Indian hospital are presented in table 2 and described in detail in online supplemental appendix 3. The costs from a UK perspective are also presented as a scenario analysis.

\section{Costs of SLET versus CLET}

The total cost savings are provided as a breakdown of the individual cost differences as shown in table 3. The costs of SLET are approximately $10 \%$ of the costs of CLET for adults and $8 \%$ of the costs of CLET for children, with SLET providing an estimated cost savings of INR 480000 for adults and INR 495000 for children.

A comparison of the total costs of SLET versus CLET is also presented in figure 4A,B, for adults and children, respectively. Most of the savings associated with SLET are due to a reduction 


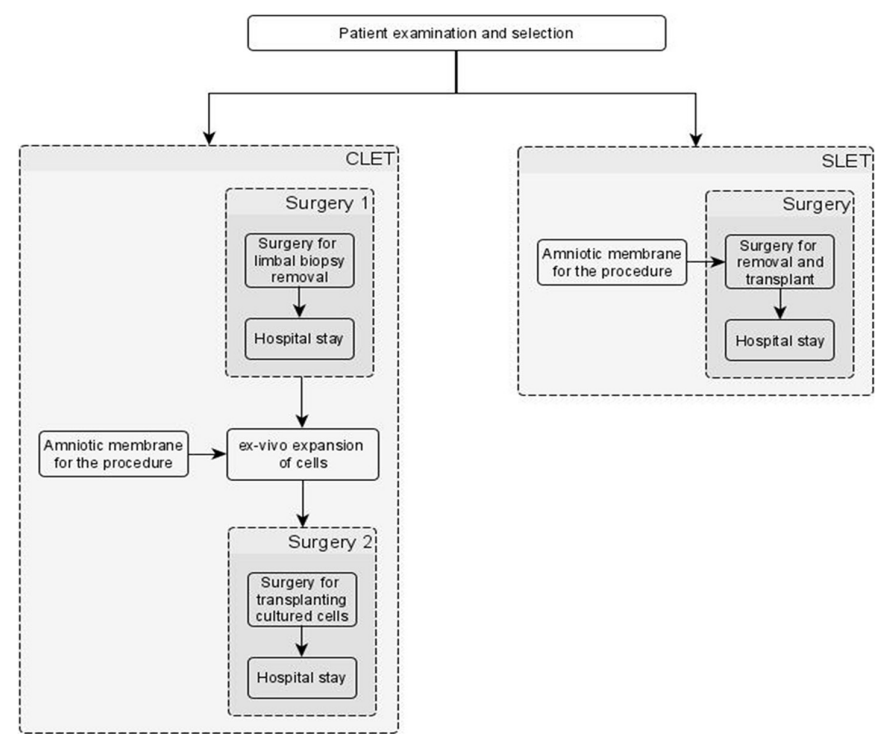

Figure 3 Flow chart of steps and procedures in CLET and SLET. CLET, cultured limbal epithelial transplantation; SLET, simple limbal epithelial transplantation.

in the need for cell culturing and the second surgery required for CLET. For children, the cost savings are higher due to the additional reduction in the anaesthesia costs.

Costs of surgery and cell culture were identified as the key cost drivers, the lower the costs of cell culture and surgery the lower the cost savings. Similarly, the higher the costs of cell culture and surgery the higher the average cost savings. This suggests that the cost savings are likely to be greater in developed countries where the costs associated with cell culture and surgery are higher. This is explored as a scenario analysis using the UK costs, which demonstrated cost savings of $£ 54061$ for each adult patient (approximately INR 5 million using an exchange rate of $1 \mathrm{GBP}=\mathrm{INR} 94$ from xe.com), as reported in online supplemental file 2 .

\begin{tabular}{|c|c|c|}
\hline Item & $\begin{array}{l}\text { Mean value } \\
\text { in INR }\end{array}$ & $\begin{array}{l}\text { Range (lower } 95 \% \mathrm{Cl} \\
\text { to upper } 95 \% \mathrm{Cl})\end{array}$ \\
\hline \multicolumn{3}{|l|}{ Costs associated with CLET } \\
\hline First CLET surgery (biopsy) & 34800 & 10300 to 86700 \\
\hline General anaesthesia* & 3600 & 2400 to 9300 \\
\hline Hospital stay* & 3000 per day & 1200 to 11000 \\
\hline Amniotic membrane & 2500 & - \\
\hline Cell culture & 437500 & 350000 to 525000 \\
\hline Second CLET surgery (transplantation) & 34800 & 10300 to 86700 \\
\hline Hospital stay* & 3000 per day & 1200 to 11000 \\
\hline General anaesthesia* & 3600 & 2400 to 9300 \\
\hline Fibrin glue & 5900 & 1800 to 14600 \\
\hline \multicolumn{3}{|l|}{ Costs associated with SLET } \\
\hline Amniotic membrane & 2500 & - \\
\hline Single SLET surgery & 34800 & 10300 to 86700 \\
\hline Hospital stay* & 3000 per day & 1200 to 11000 \\
\hline General anaesthesia* & 3600 & 2400 to 9300 \\
\hline Fibrin glue & 5900 & 1800 to 14600 \\
\hline
\end{tabular}

*Only for children.

CLET, cultured limbal epithelial transplantation; INR, Indian rupee; SLET, simple limbal epithelial transplantation.
Table 3 Breakdown of cost results in Indian rupees (INR), with costs converted to US dollars in the brackets*

\begin{tabular}{|c|c|c|c|}
\hline & CLET & SLET & $\begin{array}{l}\text { Percentage } \\
\text { average savings }\end{array}$ \\
\hline \multicolumn{4}{|l|}{ Adult patients } \\
\hline Surgery & $\begin{array}{l}\text { INR } 93958 \\
\text { (US\$1253) }\end{array}$ & $\begin{array}{l}\text { INR } 51022 \\
\text { (US\$680) }\end{array}$ & 46 \\
\hline Cell culture & $\begin{array}{l}\text { INR } 439226 \\
\text { (US\$5856) }\end{array}$ & $\begin{array}{l}\text { INR } 2496 \\
\text { (US\$33) }\end{array}$ & 99 \\
\hline Total costs & $\begin{array}{l}\text { INR } 533184 \\
\text { (US\$7110) }\end{array}$ & $\begin{array}{l}\text { INR } 53518 \\
\text { (US\$714) }\end{array}$ & 90 \\
\hline \multicolumn{4}{|l|}{ Children } \\
\hline Surgery & $\begin{array}{l}\text { INR } 94523 \\
\text { (US\$1260) }\end{array}$ & $\begin{array}{l}\text { INR } 51199 \\
\text { (US\$683) }\end{array}$ & 46 \\
\hline Hospitalisation* & $\begin{array}{l}\text { INR } 30147 \\
\text { (US\$402) }\end{array}$ & $\begin{array}{l}\text { INR } 15443 \\
\text { (US\$206) }\end{array}$ & 51 \\
\hline Cell culture & $\begin{array}{l}\text { INR } 439667 \\
\text { (US\$5862) }\end{array}$ & $\begin{array}{l}\text { INR } 2494 \\
\text { (US\$33) }\end{array}$ & 99 \\
\hline Total costs & $\begin{array}{l}\text { INR } 564337 \\
\text { (US\$7525) }\end{array}$ & $\begin{array}{l}\text { INR } 69136 \\
\text { (US\$922) }\end{array}$ & 88 \\
\hline
\end{tabular}

*Using an exchange rate of US $\$ 1=$ INR 75 , from xe.com.

\section{Social impact}

Interviews with the two clinicians involved in this study highlighted several benefits associated with SLET such as low-cost procedure, requirement of single surgery can be performed in simple clinical setting and lower risk of contamination. The details are given in online supplemental appendix 4 .

\section{DISCUSSION}

Peer-reviewed studies provide evidence from several groups that SLET has comparable clinical efficacy to CLET for adults and is slightly better for children. ${ }^{24}$ The anatomical success with SLET in adults is $72.6 \%$ (range $62 \%-80 \%$ ) and in children is $77.8 \%$ (range $73 \%-83 \%$ ). ${ }^{13}{ }^{24}$ For CLET, the anatomical success in adults is $70.4 \%$ (range $68 \%-80.9 \%$ ) and in children is 44.5 (range 43\%-45\%). ${ }^{3536}$

The figures from the recent reviews of the two techniques suggest that the number of patients that have been treated over nearly 20 years by CLET is comparable to those treated with SLET in just over 7 years. ${ }^{34}$ 37-39 The numbers from our informal survey suggest that the number of SLET surgeries has crossed the 1000 mark which, as expected, is higher than estimates from the published literature.

Our analyses suggest that SLET surgery is a cost-saving strategy when implemented for the care of patients with LSCD. A specialist eye hospital such as LVPEI is estimated to treat approximately 85 patients each year, and the estimated cost saving for replacement of CLET with SLET in such a hospital is
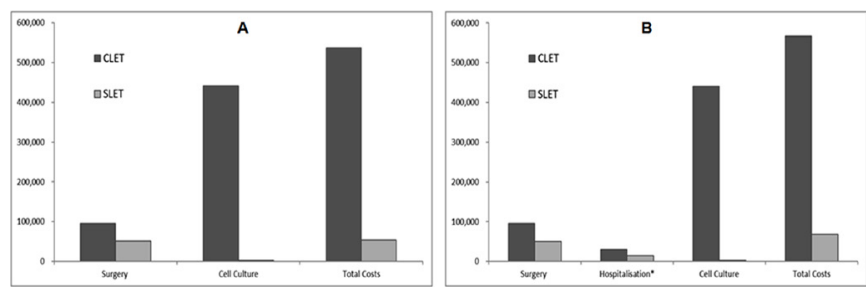

Figure 4 Graph showing the cost details of performing CLET and SLET in Indian rupees. (A) Cost for adults. (B) Cost for children. CLET, cultured limbal epithelial transplantation; SLET, simple limbal epithelial transplantation. 
therefore around INR 40 million per annum. We have provided a user-friendly Excel tool for the readers to input costs related to their setting to estimate the economic impact of SLET compared with CLET.

The results of the current analysis have important implications for eye hospitals facing rising demand. The evidence suggests that the use of SLET may substantially reduce the number of surgeries which may also alleviate pressure on beds and associated costs. Indeed, SLET has replaced CLET as the preferred surgery option for patients with LSCD and several other hospitals around the world have now established SLET.

We present a strong case for SLET likely to be more commonly adopted in the future due to issues associated with CLET such as difficulty in setting up cell culture facilities, lack of commercial cell culture services, the prohibitive cost of cell culture and the many advantages offered by SLET.

To culture cells to a standard required for regulatory approval requires highly trained cell culture staff specialised premises and an invisible, but real burden of keeping these funded and regulatory compliant year on year. All such ventures begin with research funding and indeed quite successful clinically, however, there are very few cases where these endeavours become adopted as a routine clinical service with the full cost. To the best of our knowledge, there is currently only one organisation providing laboratory expansion of autologous limbal epithelial cells as a commercial clinical service (Chiesi Farmaceutica of Palermo, Italy). In 2015, they received European Medicines Agency approval for their autologous cell therapy Holoclar (the first stem cell product to be approved in European Union), where laboratory-expanded autologous cells are grown and delivered to the patient on a fibrin mat. ${ }^{3}$ In 2018, The National Institute of Health and Care Excellence (NICE) in England and Wales gave provisional approval for the use of Holoclar based on a confidential discount, as it was acknowledged that there was no other commercially approved methodology for culturing corneal cells in the UK for clinical use (https:// www.nice.org.uk/guidance/ta467/chapter/5-Implementation).

Even when the service is set up to take on the culture of cells for clinical use, the economics of doing this meant that cost of each cell culture is prohibitive. Our costing model (online supplemental file 2)highlights the substantial costs of cell culturing (many times higher than the cost of the surgery itself). We were unable to find any such published figures in the UK or Europe, except for Holoclar as described above, where the price for culture service is listed as $£ 80000$ per eye. Provisional approval by NICE is at a confidential discount price (at a discount not disclosed) on the understanding that long-term follow-up studies are required to be published when available. At the time of writing, we have not been able to find any information on the numbers of patients treated using this approach.

On the contrary, introduction of in situ cornea regeneration on the cornea offered by SLET is immediately attractive in economic terms. It can be done in institutes that do not have access to facilities for cell culture and surgeons can be trained to undertake the SLET procedure in less than a week (and then in turn to pass on the training). From the patient's perspective, there is one rather than two surgeries so less time to be spent in hospital, and a factor of 8 -fold/10-fold savings in the costs of undertaking SLET versus CLET.

\section{CONCLUSIONS}

The published clinical data suggest that SLET is advantageous over CLET. The economic argument for using SLET rather than CLET is demonstrated in this study in a way that other centres can access it and run their analysis. In summary, simplification of
SLET technique so that cells slowly grow out of the small tissue explants to form a new cornea offers a viable, financially attractive and much more accessible approach to treat loss of vision.

\section{Author affiliations}

${ }^{1}$ Health Economics and Decision Science, The University of Sheffield School of Health and Related Research, Sheffield, UK

${ }^{2}$ Cornea and Anterior Segment Services, Dr Shroff's Charity Eye Hospital Delhi, New Delhi, Delhi, India

${ }^{3}$ Brien Holden Eye Research Center, LV Prasad Eye Institute, Hyderabad, Telangana, India

${ }^{4}$ Centre for Ocular Regeneration, LV Prasad Eye Institute, Hyderabad, Telangana, India

${ }^{5}$ Gullapalli Pratibha Rao International Centre for Advancement of Rural Eyecare, The Cornea Institute, LV Prasad Eye Institute, Hyderabad, Telangana, India

${ }^{6}$ Cornea and Anterior Segment Services, LV Prasad Eye Institute, Hyderabad,

Telangana, India

${ }^{7}$ Department of Materials Science \& Engineering, The University of Sheffield Kroto Research Institute, Sheffield, UK

${ }^{8}$ Innovation Department, Dr Shroff's Charity Eye Hospital Delhi, New Delhi, Delhi, India

Twitter Aastha Singh @aastha314

Acknowledgements We are very grateful to surgical colleagues for returning questionnaires, providing evidence of the uptake of the technique beyond the hospital of its origin and showing that it has now been practised across several countries.

Funding The study was supported by Strategic Research Fund 2020 from the Faculty of Engineering, University of Sheffield, which provided support for PT and AS, and SERB core grant (CRG/2018/003514) which provided financial support to VKS and VS to devote some of their time to find and collate the information required for this study.

\section{Competing interests None declared.}

\section{Patient consent for publication Not required.}

Provenance and peer review Not commissioned; externally peer reviewed.

Data availability statement All data relevant to the study are included in the article or uploaded as supplementary information.

Supplemental material This content has been supplied by the author(s). It has not been vetted by BMJ Publishing Group Limited (BMJ) and may not have been peer-reviewed. Any opinions or recommendations discussed are solely those of the author(s) and are not endorsed by BMJ. BMJ disclaims all liability and responsibility arising from any reliance placed on the content. Where the content includes any translated material, BMJ does not warrant the accuracy and reliability of the translations (including but not limited to local regulations, clinical guidelines, terminology, drug names and drug dosages), and is not responsible for any error and/or omissions arising from translation and adaptation or otherwise.

Open access This is an open access article distributed in accordance with the Creative Commons Attribution Non Commercial (CC BY-NC 4.0) license, which permits others to distribute, remix, adapt, build upon this work non-commercially, and license their derivative works on different terms, provided the original work is properly cited, appropriate credit is given, any changes made indicated, and the use is non-commercial. See: http://creativecommons.org/licenses/by-nc/4.0/.

\section{ORCID iDs}

Varsha M Rathi http://orcid.org/0000-0002-5422-0290

Sayan Basu http://orcid.org/0000-0001-5030-5003

Vivek Singh http://orcid.org/0000-0003-3958-5635

\section{REFERENCES}

1 Sehic A, Utheim Øygunn Aass, Ommundsen K, et al. Pre-Clinical cell-based therapy for limbal stem cell deficiency. J Funct Biomater 2015;6:863-88.

2 Vemuganti GK, Sangwan VS. Interview: affordability at the cutting edge: stem cell therapy for ocular surface reconstruction. Regen Med 2010;5:337-40.

3 Pellegrini G, Ardigò D, Milazzo G, et al. Navigating market authorization: the path Holoclar took to become the first stem cell product Approved in the European Union. Stem Cells Trans/ Med 2018;7:146-54. doi:10.1002/sctm.17-0003

4 Sangwan VS, Basu S, MacNeil S, et al. Simple limbal epithelial transplantation (SLET): a novel surgical technique for the treatment of unilateral limbal stem cell deficiency. Br J Ophthalmol 2012;96:931-4. doi:10.1136/bjophthalmol-2011-301164

5 Bhalekar S, Basu S, Lal I, et al. Successful autologous simple limbal epithelial transplantation (SLET) in previously failed paediatric limbal transplantation for ocular surface burns. BMJ Case Rep 2013;2013:bcr2013009888. 
6 Vazirani J, Basu S, Sangwan V. Successful simple limbal epithelial transplantation (SLET) in lime injury-induced limbal stem cell deficiency with ocular surface granuloma. BMJ Case Rep 2013;2013:bcr2013009405

7 Amescua G, Atallah M, Nikpoor N, et al. Modified simple limbal epithelial transplantation using cryopreserved amniotic membrane for unilateral limbal stem cell deficiency. Am J Ophthalmol 2014;158:469-75.

8 Das S, Basu S, Sangwan V. Molten metal ocular burn: long-term outcome using simple limbal epithelial transplantation. BMJ Case Rep 2015;2015:bcr2014209272.

9 Hernández-Bogantes E, Amescua G, Navas A, et al. Minor ipsilateral simple limbal epithelial transplantation (mini-SLET) for pterygium treatment. Br J Ophthalmol 2015;99:1598-600. doi:10.1136/bjophthalmol-2015-306857

10 Nair D, Mohamed A, Sangwan VS. Outcome of cataract surgery following simple limbal epithelial transplantation for lime injury-induced limbal stem cell deficiency. BMJ Case Rep 2015;2015:bcr2015212613.

11 Vazirani J, Lal I, Sangwan V. Customised simple limbal epithelial transplantation for recurrent limbal stem cell deficiency. BMJ Case Rep 2015;2015:bcr2015209429. doi:10.1136/bcr-2015-209429

12 Arya SK, Bhatti A, Raj A, et al. Simple limbal epithelial transplantation in acid injury and severe dry eye. J Clin Diagn Res 2016:10:ND06-7-7.

13 Basu S, Sureka SP, Shanbhag SS, et al. Simple limbal epithelial transplantation: long-term clinical outcomes in 125 cases of unilateral chronic ocular surface burns. Ophthalmology 2016;123:1000-10-10

14 Mittal V, Jain R, Mittal R, et al. Successful management of severe unilateral chemical burns in children using simple limbal epithelial transplantation (SLET). Br J Ophthalmol 2016;100:1102-8.

15 Mittal V, Narang P, Menon V, et al. Primary simple limbal epithelial transplantation along with excisional biopsy in the management of extensive ocular surface squamous neoplasia. Cornea 2016:35:1650-2.

16 Queiroz AG, Barbosa MMO, Santos MS, et al. Assessment of surgical outcomes of limbal transplantation using simple limbal epithelial transplantation technique in patients with total unilateral limbal deficiency. Arq Bras Oftalmol 2016;79:116-8-8.

17 Vazirani J, Ali MH, Sharma N, et al. Autologous simple limbal epithelial transplantation for unilateral limbal stem cell deficiency: multicentre results. Br J Ophthalmol 2016;100:1416-20.

18 Arora R, Dokania P, Manudhane A, et al. Preliminary results from the comparison of simple limbal epithelial transplantation with conjunctival limbal autologous transplantation in severe unilateral chronic ocular burns. Indian J Ophthalmol 2017;65:35-40-40. doi:10.4103/0301-4738.202312

19 Iyer G, Srinivasan B, Agarwal S, et al. Outcome of allo simple limbal epithelial transplantation (alloSLET) in the early stage of ocular chemical injury. Br J Ophthalmol 2017;101:828-33.

20 Kaliki S, Mohammad FA, Tahiliani P, et al. Concomitant simple limbal epithelial transplantation after surgical excision of ocular surface squamous neoplasia. Am J Ophthalmol 2017:174:68-75.

21 Singh D, Vanathi M, Gupta C, et al. Outcomes of deep anterior lamellar keratoplasty following autologous simple limbal epithelial transplant in pediatric unilateral severe chemical injury. Indian J Ophthalmo/ 2017;65:217-222-22.

22 Basu S, Mohan S, Bhalekar S, et al. Simple limbal epithelial transplantation (SLET) in failed cultivated limbal epithelial transplantation (CLET) for unilateral chronic ocular burns. Br J Ophthalmol 2018;102:1640-5.

23 Gupta N, Farooqui JH, Patel N, et al. Early results of penetrating keratoplasty in patients with unilateral chemical injury after simple limbal epithelial transplantation. Cornea 2018:37:1249-54.
24 Gupta N, Joshi J, Farooqui JH, et al. Results of simple limbal epithelial transplantation in unilateral ocular surface burn. Indian J Ophthalmol 2018;66:45-52

25 Mednick Z, Boutin T, Einan-Lifshitz A, et al. Simple limbal epithelial transplantation for recurrent pterygium: a case series. Am J Ophthalmol Case Rep 2018;12:5-8.

26 Narang P, Mittal V, Menon V, et al. Primary limbal stem cell transplantation in the surgical management of extensive ocular surface squamous neoplasia involving the limbus. Indian J Ophthalmol 2018:66:1569-1573-73.

27 Vasquez-Perez A, Nanavaty MA. Modified allogenic simple limbal epithelial transplantation followed by keratoplasty as treatment for total limbal stem cell deficiency. Ocul Immunol Inflamm 2018;26:1189-91.

28 Boutin T, Mednick Z, Zhou TE, et al. Simple limbal epithelial transplantation to treat recurring kissing pterygium. Can J Ophthalmol 2019;54:e54-7.

29 Gupta N, Singh A, Mathur U. Scleral ischemia in acute ocular chemical injury: long-term impact on rehabilitation with limbal stem cell therapy. Cornea 2019;38:198-202.

$30 \mathrm{Hu}$ XD, Yu J, Li SY, et al. [Clinical observation of autologous simple limbal epithelial transplantation for unilateral limbal stem cell deficiency]. Zhonghua Yan Ke Za Zhi 2019:55:923-7.

31 Sati A, Banerjee S, Kumar P, et al. Mini-Simple limbal epithelial transplantation versus conjunctival autograft fixation with fibrin glue after pterygium excision: a randomized controlled trial. Cornea 2019:38:1345-50.

32 Shah SG, Shah SM, Agarwal J, et al. Feasibility and outcome of simple limbal epithelia transplantation (SLET) in unilateral total limbal stem cell deficiency (LSCD) following chemical injury, in a semiurban location in Western India. Indian J Ophthalmol 2019:67:1382-3.

33 Riedl JC, Musayeva A, Wasielica-Poslednik J, et al. Allogenic simple limbal epithelial transplantation (alloSLET) from cadaveric donor eyes in patients with persistent corneal epithelial defects. Br J Ophthalmol 2021;105:180-5.

34 Shanbhag SS, Nikpoor N, Rao Donthineni P, et al. Autologous limbal stem cell transplantation: a systematic review of clinical outcomes with different surgical techniques. Br J Ophthalmol 2020;104:247-53.

35 Sejpal K, Ali MH, Maddileti S, et al. Cultivated limbal epithelial transplantation in children with ocular surface burns. JAMA Ophthalmol 2013;131:731-6.

36 Ganger A, Vanathi M, Mohanty S, et al. Long-Term outcomes of cultivated limbal epithelial transplantation: evaluation and comparison of results in children and adults. Biomed Res Int 2015:2015:1-6.

37 Shanbhag SS, Patel CN, Goyal R, et al. Simple limbal epithelial transplantation (SLET): review of indications, surgical technique, mechanism, outcomes, limitations, and impact. Indian J Ophthalmol 2019;67:1265-1277-77.

38 Jackson CJ, Myklebust Ernø IT, Ringstad H, et al. Simple limbal epithelial transplantation: current status and future perspectives. Stem Cells Trans/ Med 2020:9:316-27.

39 Shukla S, Shanbhag SS, Tavakkoli F, et al. Limbal epithelial and mesenchymal stem cell therapy for corneal regeneration. Curr Eye Res 2020;45:265-77.

40 Rama P, Matuska S, Paganoni G, et al. Limbal stem-cell therapy and long-term cornea regeneration. N Engl J Med 2010;363:147-55

41 Pauklin M, Fuchsluger TA, Westekemper $\mathrm{H}$, et al. Midterm results of cultivated autologous and allogeneic limbal epithelial transplantation in limbal stem cell deficiency. Dev Ophthalmol 2010;45:57-70.

42 Fasolo A, Pedrotti E, Passilongo M, et al. Safety outcomes and long-term effectiveness of ex vivo autologous cultured limbal epithelial transplantation for limbal stem cell deficiency. Br J Ophthalmol 2017;101:640-9. 